\title{
The application of Reiki in nurses diagnosed with Burnout Syndrome has beneficial effects on concentration of salivary IgA and blood pressure
}

\author{
Lourdes Díaz-Rodríguez ${ }^{1}$ \\ Manuel Arroyo-Morales ${ }^{2}$ \\ Irene Cantarero-Villanueva ${ }^{3}$ \\ Carolina Férnandez-Lao ${ }^{4}$ \\ Marie Polley \\ César Fernández-de-las-Peñas ${ }^{6}$
}

This study aimed to investigate the immediate effects of the secretory immunoglobulin A ( $\operatorname{Ig} A)$, a-amylase activity and blood pressure levels after the application of a Reiki session in nurses with Burnout Syndrome. A randomized, double-blind, placebo-controlled, crossover design was conducted to compare the immediate effects of Reiki versus control intervention (Hand-off sham intervention) in nurses with Burnout Syndrome. Sample was composed of eighteen nurses (aged 34-56 years) with burnout syndrome. Participants were randomly assigned to receive either a Reiki treatment or a placebo (sham Reiki) treatment, according to the established order in two different days. The ANOVA showed a significant interaction time $\mathrm{x}$ intervention for diastolic blood pressure $(F=4.92, P=0.04)$ and sIgA concentration $(F=4.71, P=0.04)$. A Reiki session can produce an immediate and statistically significant improvement in SIgA concentration and diastolic blood pressure in nurses with Burnout Syndrome.

Descriptors: Burnout, Professional; Therapeutic Touch; Immunoglobulin A; Blood Pressure; Alpha-Amylases; Nursing.

\footnotetext{
${ }^{1}$ RN, Anthropologist, Ph.D. in Nursing, Assistant Professor, Departamento de Enfermería, Universidad de Granada, Spain. E-mail: cldiaz@ugr.es.

2 Physician, Ph.D. in Medicine, Full Professor, Departamento de Fisioterapia, Universidad de Granada, Spain. E-mail: marroyo@ugr.es.

${ }^{3}$ Physical Educator, Physical Therapist, M.Sc. in Physical Education, Research scholarship holder, Departamento de Fisioterapia, Universidad de Granada, Spain. E-mail: irenecantarero@ugr.es.

${ }^{4}$ Librarian, Physical Therapist, M.Sc. in Social Anthropology, Research scholarship holder, Universidad de Granada, Spain. E-mail: carolinafı@ugr.es.

${ }^{5}$ Ph.D. in Life Sciences, Professor, University of Westminster, London, United Kingdon. E-mail: M.Polley01@westminster.co.uk.

${ }^{6}$ Physical Therapist, Ph.D. in Physical Therapy, Full Professor, Departamento de Fisioterapia, Terapia Ocupacional y Rehabilitación, Facultad Ciencias de La Salud, Universidad Rey Juan Carlos, Madrid, Spain. E-mail: cesarfdlp@yahoo.es.
} 


\title{
Uma sessão de Reiki em enfermeiras diagnosticadas com síndrome de Burnout tem efeitos benéficos sobre a concentração de IgA salivar e a pressão arterial
}

O objetivo deste estudo foi investigar os efeitos imediatos na imunoglobulina A salivar (IgAs), na atividade de a-amilase e na pressão arterial, após uma aplicação de Reiki em enfermeiras que sofrem da síndrome de Burnout. Foi realizado ensaio clínico randomizado duplo-cego e placebo controlado, com desenho cruzado. Dezoito enfermeiras (idade entre 34 e 56 anos), com síndrome de Burnout, participaram do estudo. As participantes receberam tratamento com Reiki ou Reiki falso, de acordo com a ordem estabelecida, através da randomização em dois dias distintos. $O$ teste de Anova mostrou interação significativa entre o momento da intervenção e a pressão arterial diastólica $(F=4,92$, $p=0,04)$ e os níveis de sIgA $(F=4,71, p=0,04)$. Conclui-se que uma sessão de Reiki de 30 minutos pode melhorar de forma imediata a resposta de IgAs e da pressão arterial diastólica em enfermeiras com síndrome de Burnout.

Descritores: Esgotamento Profissional; Toque Terapêutico; Imunoglobulina A; Pressão Arterial; Alfa-Amilase; Enfermagem.

\section{Una sesión de Reiki en enfermeras diagnosticadas con síndrome de Burnout tiene efectos beneficiosos sobre la concentración de IgA salival y la presión arterial}

\begin{abstract}
El objetivo fue investigar los efectos inmediatos en inmunoglobulina A salival (IgAs), actividad de a-amilasa y presión arterial de una aplicación de reiki en enfermeras sufriendo síndrome de Burnout. Se utilizó un ensayo preliminar placebo randomizado con cegamiento doble utilizando un diseño cruzado. Dieciocho enfermeras (edad 3456) con síndrome de Burnout participaron en el estudio. Las participantes recibieron tratamiento con Reiki o Reiki fingido según el orden establecido por la randomización en dos días distintos. El test de ANOVA mostró un interacción significativa momento intervención para la presión arterial diastólica $(F=4.92, P=0.04)$ a y la concentración de SIgA $(F=4.71, P=0.04)$. Una sesión de Reiki de 30 minutos puede mejorar de manera inmediata la respuesta de IgAs y la presión arterial diastólica en enfermeras con síndrome de Burnout.
\end{abstract}

Descriptores: Agotamiento Profesional; Tacto Terapéutico; Inmunoglobulina A; Presión Sanguínea; Alfa-Amilasa; Enfermería.

\section{Introduction}

Burnout syndrome (BS) is a prolonged response to chronic emotional and interpersonal job stressors. Nurses are particularly at risk of occupational burnout due to their highly, physically and emotionally demanding job. In fact studies report a frequency of BS in nurse professionals of up to $40 \%{ }^{(1-2)}$. Frequently, BS is associated with low job satisfaction, stressful emotional interaction, and musculoskeletal pain. It has been suggested that these stress-related health problems can alter several immunological processes(3).
Furthermore, reduced activation or efficacy of the immune and central nervous system associated with job stress has been postulated as a risk factor in the contraction of various infections(3).

Proactively caring for one's self through Reiki, for instance, is a strategy that is increasingly being recognized as preventing $B S$ in nurses. Reiki is a mind-body medicine that aims to help replenish and re-balance the body's natural energetic system by stimulating natural healing processes ${ }^{(4-5)}$. It is often 
used to induce relaxation and treat conditions such as musculoskeletal pain, anxiety and depression. Reike practitioners channel life force energy to themselves and the patient using a light or no touch approach. Nurses who used Reiki for self care found that it helped with stress management and lessening burnout symptoms ${ }^{(6-7)}$. The reported stress management benefits included achieving a state of relaxation, calmness, and having more clarity of thought, even after very short Reiki self-treatments. Furthermore, nurses felt that Reiki helped them be more resilient to stresses of their working environment(7).

It is important to treat both the physical and emotional states in nurses suffering $\mathrm{BS}^{(8)}$. Since nurses using Reiki as self-care report that it provides protection against BS, it is therefore likely that nurses suffering with BS may benefit from receiving a Reiki treatment. A recent review concluded that current evidence is insufficient to suggest that Reiki is an effective treatment ${ }^{(9-10)}$ although it is recommended for different professionals ${ }^{(9)}$.

The complex body/mind relationship is regulated by the autonomic, endocrine and immune systems. Activity in any of these systems can modulate activity of the others ${ }^{(3)}$. The physiological stress response in BS includes stimulation of the sympathetic nervous system (SNS) such as elevated blood pressure and reduction of the immune response ${ }^{(11)}$. Several biological markers are widely used to measure the physiological stress response such as salivary $\alpha$-amylase, immunoglobulin $A$, and blood pressure; and they are all associated with the SNS. Alpha-amylase ( $\alpha$-amylase) is a marker of sympathetic activity that accounts for about one-half of the total protein in saliva and functions to interrupt the adherence and growth of certain bacteria(12). $\operatorname{sigA}$ is a first-line of defense against pathogenic microorganisms and is found in external secretions that bathe oral mucosal surfaces. sIgA production is lowered in response to high levels of perceived stress and $\mathrm{BS}^{(13)}$. Similarly blood pressure is a non-invasive measure associated with the autonomic nervous system. Interestingly, different hands on/off techniques (including Reiki), have demonstrated positive effects on blood pressure ${ }^{(4-}$ ${ }^{5,14)}$ and S-IgA in healthy people ${ }^{(5,15)}$. To the best of the authors' knowledge, no previous study has investigated the effects of Reiki on salivary $\alpha$-amylase.

Since the effect of Reiki treatment has been not previously investigated in nurses suffering BS, it is not known if similar changes in blood pressure, sIgA and salivary amylase would be present. Although a reduction in influence of autonomic nervous system and thus an increase in IgA and a decrease in blood pressure would be anticipated after a Reiki session, recent research suggests that the body may intermittently recalibrate physiological markers in response to $\mathrm{BS}^{(16)}$. It is therefore important to establish which biological markers are suitable for measuring change when treating BS with Reiki.

The main objective of this study was to investigate if any immediate effects in $\operatorname{sIgA} \alpha$-amylase activity and blood pressure levels could be measured after the application of a single 30 minute Reiki session in nurses with BS.

\section{Methods}

\section{Participants}

Eighteen female nurses with a diagnosis of BS were recruited at the University Hospital San Cecilio (Granada, Spain) between January and July 2009. Participants were diagnosed with BS by a psychologist experienced in the management of these patients, according to criteria established by Maslach(17). BS features, health service, job history, and medications were collected by the psychologist. To be eligible, participants had to describe all the features typical of BS (depersonalization, emotional exhaustion and low personal accomplishment leading to decreased work effectiveness)(17). Ethical approval was granted by the Local Hospital Ethics Committee. Informed consent was obtained from all participants and procedures were conducted according to the Declaration of Helsinki.

\section{Experimental Design}

The study was randomized, double-blind, placebocontrolled, using a crossover design, and conducted to compare the immediate effects of Reiki versus placebo (sham Reiki) in nurses with BS. Potential participants were screened for eligibility and introduced to the study. After completing informed consent forms, a brief demographic form from the participants was taken. Neither the participants nor the data collectors knew which participants were in which group. Participants arrived at the laboratory at between 9-12 am in two separate occasions to avoid circadian rhythm-induced variations. Treatment sessions were carried at one week intervals. Participants were instructed not to take any anxiolytic or analgesic drug for approximately 48 
hours prior to the experimental session. Participants were also requested to abstain from caffeine, alcohol, food and exercise for $2 \mathrm{~h}$ prior to taking part in the study to reduce the influence of these substances on saliva measurements. In the first session, all participants rested in a supine position for 20 minutes. Baseline measurements of blood pressure (in triplicate) were then taken and a stimulated saliva sample ( $3 \mathrm{~min}$ ) was collected. Immediately after collection, saliva samples were centrifuged at $3000 \mathrm{rpm}$ for $15 \mathrm{~min}$ to remove any sediment and were stored at $-70^{\circ} \mathrm{C}$ until analysis.

Participants were then randomly assigned to either the Reiki treatment or placebo group using the face of a coin method. The intervention and placebo were carried out as previously described ${ }^{(13)}$. Briefly, the Reiki treatment was administered by the same therapist with more than 15 years of clinical experience in Usui Reiki (Level 3). Participants were fully clothed and the Reiki practitioner placed their hands over various parts of the body (without touching), for approximately 5 minutes before changing hand positions. Areas treated were primarily around the head, eyes, ears and chest and the treatment lasted for a total of 30 minutes. The placebo intervention was administered by a nurse without experience in Reiki but mimicking the Reiki intervention as much as possible e.g using the same hand positions for approximately 5 minutes. The nurse focused attention in neutral stimulus with no healing intentions during the placebo session. The placebo intervention hast the same duration that experimental session.

Immediately following the intervention, posttreatment saliva samples and BP measurements (in triplicate) were taken. As before, the salivary samples were centrifuged at $3000 \mathrm{rpm}$ for $15 \mathrm{~min}$ to remove any sediment and were stored at $-70^{\circ} \mathrm{C}$ until further analysis. All salivary samples and BP measurements were performed by an assessor blinded to the treatment allocation of the participants.

\section{Salivary measurements}

Secretory immunoglobulin A ( $\operatorname{SIgA}$ ) in saliva was quantitatively measured using the validated indirect competitive immunoassay kit - SIgA (Salimetrics TM State College, USA). Luminescence units were read using a microplate absorbance reader (Sunrise TM TECAN, Männedorf, Switzeland). Salivary a-amylase activity was quantified using the validated alpha- amylase kit - (SalimetricsTM, State College, USA). Results were read using a microplate absorbance reader at 405nm (SunriseTM TECAN, Männedorf, Switzeland). All samples were analyzed in a single batch to eliminate inter-assay variance and were measured in duplicate. Adequate intra-assay accuracy was obtained with a coefficient of variance $<6,5 \%$.

\section{Blood pressure measurements}

An Omron HEM-737 validated automatic oscillometric device (Kyoto, Japan) was used for BP measurements. Measurements were performed in triplicate and the average was used for data analysis.

\section{Statistical analysis}

Data were analyzed through the $\mathrm{R}$ software (version 2.9.2, Auckland, New Zealand). Mean, standard deviations and 95\% confidence intervals were calculated for each variable. The effect of the intervention was examined using a 2-way analysis of variance (ANOVA). The intervention (experimental, placebo) was the between-participants variable and time (pre-post) was the within-participants variable. Separate ANOVAs were performed with each dependent variable. The hypothesis of interest was intervention $x$ time interaction. If a significant interaction was identified, pair-wise comparisons were performed to investigate if between-group differences in change scores were statistically significant. A P value less than .05 was considered statistically significant.

\section{Results}

Participants were all female, hispanic, aged between 34 and 56 years (mean age 43.7yrs, SD: 6.2) and highly educated (education levels from 9 to 18 years; M: 13.2; SD: 4.7). All participants had previously experienced some type of complementary therapy such as massage, meditation or yoga. All participants completed the protocol and the results from all of them were used in the main analysis. Therefore, 18 female nurses, mean weight $60.5 \pm 8.3 \mathrm{Kg}(95 \% \mathrm{CI} 56,64 \mathrm{Kg}$ )), mean height $160 \pm 4 \mathrm{~cm}(95 \% \mathrm{CI} 158,163 \mathrm{~cm}$.$) and mean BMI$ $27.7 \pm 5.1 \mathrm{~kg} / \mathrm{m} 2(95 \%$ CI $25,30 \mathrm{Kg} / \mathrm{m} 2)$ were included (Table 1). Pre-intervention data of each variable were not significantly different between conditions: SIgA concentration $(P=0.92)$, a-amylase activity $(P=0.12)$, systolic $B P(P=0.91)$ and diastolic $B P(P=0.85)$. 
Table 1 - Characteristics of participants who completed study $(n=18)$

\begin{tabular}{lc}
\hline \multicolumn{1}{c}{ Characteristic } & Data \\
\hline Hospital Unit (\%) & \\
Emergency & $14(77.8)$ \\
Intensive Care & $4(22.2)$ \\
Work experience (\%) & \\
$0-5$ years & $6(33.3)$ \\
6-10 years & $5(27.8)$ \\
$>11$ years & $7(38.9)$ \\
Number married (\%) & $9(50.0)$ \\
Mean number of dependent children (range) & $1.33(1-2)$ \\
\hline
\end{tabular}

The ANOVA showed a significant interaction time $x$ intervention for diastolic blood pressure $(F=4.92$, $\mathrm{P}=0.04)$ and $\operatorname{sigA}$ concentration $(\mathrm{F}=4.71, \mathrm{P}=0.04)$, but not for $\alpha$-amylase activity $(F=0.14 ; P=0.71)$ or systolic $\mathrm{BP}(\mathrm{F}=2.88 ; \mathrm{P}=0.24)$. Interestingly, pair-wise comparisons found that the participants who received Reiki treatment showed a statistically significant increase in the SIgA concentration ( $P=0.03)$, compared to a nonsignificant decrease in the placebo group $(P=0.33$ ) (Table 2). Participants also showed a statistically significant decrease in diastolic BP $(P=0.04)$, after the Reiki session compared to no change after the placebo $(P=0.82)$.

Table 2 details pre-post intervention and change scores of salivary markers and BP measurements.

Table 2 - Pre-intervention, post-intervention and change scores of salivary markers and blood pressure after each session

\begin{tabular}{|c|c|c|}
\hline$n=18$ & Placebo session & Reiki session \\
\hline \multicolumn{3}{|l|}{ DB pressure $(\mathrm{mm} \mathrm{Hg})$} \\
\hline Baseline & $70.8 \pm 7.6(95 \% \mathrm{Cl} 66.0-75.7)$ & $71.1 \pm 8.8(95 \% \mathrm{Cl} 65.4-76.8)$ \\
\hline Post-Intervention & $71.2 \pm 9.1(95 \% \mathrm{Cl} 65.4-77.1)$ & $66.6 \pm 7.9(95 \% \mathrm{Cl} 61.6-71.7)$ \\
\hline Pre-post change & $0.4(95 \% \mathrm{Cl}-3.7 / 4.5)$ & $-4.5(95 \% \mathrm{Cl}-0.6 /-9.7)^{\star}$ \\
\hline \multicolumn{3}{|l|}{ SB pressure $(\mathrm{mm} \mathrm{Hg})$} \\
\hline Baseline & $115.4 \pm 13.1(95 \% \mathrm{Cl} 107.1-123.7)$ & $115.7 \pm 12.0(95 \% \mathrm{Cl} 108.1-123.4)$ \\
\hline Post-Intervention & $113.6 \pm 14.2(95 \% \mathrm{Cl} 104.6-122.6)$ & $109.2 \pm 12.3(95 \% \mathrm{Cl} 101.4-117.1)$ \\
\hline Pre-post change & $-1.8(95 \% \mathrm{Cl}-0.2 / 0.3)$ & $-6.5(95 \% \mathrm{Cl}-11.1 /-1.8)$ \\
\hline \multicolumn{3}{|l|}{$\operatorname{slgA}(\mu g / m l)$} \\
\hline Baseline & $21.52 \pm 6.67(95 \% \mathrm{Cl} 18.3-24.7)$ & $21.56 \pm 6.76(95 \% \mathrm{Cl} 18.3-24.8)$ \\
\hline Post-Intervention & $19.58 \pm 9.91(95 \% \mathrm{Cl} 14.8-24.3)$ & $25.51 \pm 8.00(95 \% \mathrm{Cl} 21.6-29.3)$ \\
\hline Pre-post change & $-1.94(95 \% \mathrm{Cl}-6.2$ / 2.29) & $3.95(95 \% \mathrm{Cl} 1.6 / 7.3)^{*}$ \\
\hline \multicolumn{3}{|l|}{ A-amylase activity (U/ml) } \\
\hline Baseline & $149.3 \pm 89.4(95 \%$ Cl $103.4-195.3)$ & $171.0 \pm 100.2(95 \% \mathrm{Cl} 119.5-222.4)$ \\
\hline Post-Intervention & $171.0 \pm 105.0(95 \% \mathrm{Cl} 117.0-225.0)$ & $201.4 \pm 165.5(95 \%$ Cl $16.8-287.0)$ \\
\hline Pre-post change & $21.7(95 \% \mathrm{Cl}-31.4$ / 54.5) & $30.4(\mathrm{Cl} 95 \% 1.9 / 45.2)$ \\
\hline
\end{tabular}

Values are expressed as mean \pm standard deviation ( $95 \%$ confidence interval) for baseline and post-intervention data as mean ( $95 \%$ confidence interval) for pre-post change. * Statistical significant $(\mathrm{P}<0.05)$

\section{Discussion}

Results showed that a single Reiki treatment produced a statistically significant increase in s-IgA and diastolic blood pressure, but not in a-amylase activity or systolic blood pressure in nurses with BS, whereas the placebo Reiki group showed no significant changes in blood pressure or salivary markers. These results indicate that Reiki can increase the unspecific sIgA immune response when applied to nurses suffering with BS. Similar changes in SIgA have previously been reported in a group of healthy participants of a randomized and non-controlled study(4). The $\operatorname{sIgA}$ is a measure of generalized humoral immune function, which has been associated to produce relaxation effects ${ }^{(15,18)}$. The precise mechanism underlying the Reiki-induced increase in sIgA concentration is not yet well understood. Salivary glands are controlled by both the sympathetic and parasympathetic systems hence, it is possible that Reiki enhances sIgA secretion by stimulating the autonomic nervous system.

The intervention group in this study only received a single Reiki treatment of 30 minutes. An researcher ${ }^{(7)}$, when interviewing nurses who use Reiki for self-care, also noted how nurses used Reiki for only a few minutes during their busy day to relax and calm themselves. Taken together, these data support the idea that relatively brief but effective relaxation sessions, such as 
a Reiki, treatment can significantly relieve the negative effects of job stress on specific aspects of the immune system in nurses suffering from BS.

An important finding of this study was that Reiki enhanced the diastolic blood pressure in nurses suffering from BS. The capacity of Reiki to modify BP levels has been shown in previous studies in healthy people(4-5) but not in animals(19). Differences between human and animal studies led researchers to offer a mixed psychological-physiological explanation of the influence of Reiki on BP. The significant decrease in diastolic BP in this study could be due to Reiki influencing the ANS which may then reduce peripheral vascular resistance, probably through reduced sympathetic outflow to the resistance blood vessels( ${ }^{(15)}$. The reduction of BP and sedative effects of touch-like techniques observed in animals has also been reported to involve opiate and serotonergic mechanisms, which may also be implicated as a mechanism of action in this study ${ }^{(20)}$. Further studies monitoring opiate and serotoninergic mechanisms would be required to confirm the importance of these substances in immediate effects of Reiki.

Nevertheless, neither $\alpha$-amylase activity nor systolic BP had significant changes between the Reiki and placebo sessions, although systolic BP levels did show no significant decrease after the Reiki session. Our results are similar to those previously reported by different hands-on touch therapies ${ }^{(14,20)}$. Previous and current data suggest that a single session of Reiki is unable to reduce $\alpha$-amylase activity. However, it is not known whether changes in salivary a-amylase activity would be present after 2,6 , or 24 hours. Interestingly, recent research(16) that measured a range of biological stress markers in 30 participants reported that participants with increased allostatic load had increased reports of chronic stress and BS and a hypocortisolemic profile(16). Thus the salivary stress markers may have altered baseline characteristic due to the body's maladaptive approach to dealing with the chronic and repeated exposure to stress in burnout situations. It is possible that the lack of response in salivary amylase is due to altered baseline level of $\alpha$-amylase activity in nurses suffering BS.

The main strength of this study is the randomized, double blind design which reduces several methodological flaws described in previous systematic reviews ${ }^{(9-10)}$. Three major advantages of this study design are: 1 , a cross-over design can reduce variability in the subject responses, reducing lost of power associated with small sample sizes; 2 , economy of the size sample; 3 , adequate control strategy for this type of studies ${ }^{(21)}$.
There are also some limitations of the current study. Firstly, immediate effects obtained without long-term follow-ups may have limited clinical significance. This was, however, a conservative Reiki treatment lasting for only 30 minutes. Usual Reiki treatments often last for approximately 1 hour and patients may receive a course of Reiki treatments to regain their health. The fact that such biological changes can be achieved in such a short space of time demonstrates the potential to achieve clinically relevant improvements in health. Secondly, we used stimulated salivary samples, which could have influenced in a-amylase activity(12). It would be interesting to investigate long-term effects of Reiki treatment in nurses suffering BS using non-stimulated saliva sample. Finally, only women were included in this study to get a homogeneous group following previous research of our group which has found a better s-Iga response in womem after recovery techniques ${ }^{(15)}$.

\section{Conclusion}

In conclusion, a single Reiki treatment in this study led to an immediate improvement of both innate immune function ( $\operatorname{SIgA})$ and $\mathrm{BP}$ regulation. Furthermore the application of Reiki treatments could be a cost effective approach for managing and preventing the negative effects of job stress in nurse subgroups with a high risk profile for BS.

\section{References}

1. Atance-Martinez JC. Epidemiologic aspects of the burnout syndrome in hospital personnel. Rev Esp Salud Publica. 1997;71:293-303.

2. Irving JA, Dobkin PL, Park J. Cultivating mindfulness in health care professionals: A review of empirical studies of mindfulness-based stress reduction (MBSR). Complement Ther Clin Pract. 2009;15:61-6.

3. Mommersteeg PM, Heijnen $\mathrm{CJ}$, Kavelaars $\mathrm{A}$, van Doornen LJ. The HPA axis and immune function in burnout. Prog Brain Res. 2008;167:281-5.

4. Wardell DW, Engebretson J. Biological correlates of Reiki touchsm healing. J Adv Nurs. 2001;33:439-45.

5. Mackay N, Hansen S, McFarlane O. Autonomic nervous system changes during Reiki treatment: A preliminary study. J Altern Complement Med. 2004;10:1077-81.

6 Whelan KM, Wishnia GS. Reiki therapy: the benefits to a nurse/Reiki practitioner. Holist Nurs Pract. 2003;17(4):209-17.

7. Vitale A. Nurses' lived experience of Reiki for selfcare. Holist Nurs Pract. 2009; 23(3):129-41, 142-5; quiz 146-7. 
8. VandenTooren $M$, de Jonge J. Managing job stress in nursing: what kind of resources do we need? J Adv Nurs. 2008;63:75-84.

9. Lee MS, Pittler MH, Ernst E. Effects of Reiki in clinical practice: a systematic review of randomized clinical trials. Int J Clin Pract. 2008;62:947-54.

10. vanderVaart S, Gijsen VM, de Wildt SN, Koren G. A systematic review of the therapeutic effects of Reiki. J Altern Complement Med. 2009;15:1157-69.

11. Murofuse NT, Abranches SS, Napoleão AA. Reflexões sobre estresse e Burnout e a relação com a enfermagem. Rev. Latino-Am. Enfermagem. março-abril 2005;13(2):255-61.

12. NaterUM, RohlederN. Salivaryalpha-amylase asa noninvasive biomarker for the sympathetic nervous system: current state of research. Psychoneuroendocrinology 2009;34:486-96.

13. Wright BJ. Comparing the job strain and job demand-control-support models in direct-care disability workers: support for support. J Occup Environ Med. 2008; 50:316-23.

14. Arroyo-Morales M, Olea N, Martínez MM, HidalgoLozano A, Ruiz-Rodríguez C, Díaz-Rodríguez L. Psychophysiological effects of massage-myofascial release after exercise: a randomized sham-control study.

] Altern Complement Med. 2008;14:1223-9.

15. Arroyo-Morales M, Olea N, Ruíz C, del Castillo JD, Martínez M, Lorenzo $C$, et al. Massage after exerciseresponses of immunologic and endocrine markers: a randomized single-blind placebo-controlled study. J Strength Cond Res. 2009;23:638-44.

16. Juster SP, Sindi S, Marin MF, Perna A, Hashemi A, Pruessner JC, Lupien SJ. A clinical allostatic load index is associated with burnout symptoms and hypocortisolemic profiles in healthy workers. Psychoneuroendocrinology 2010 Dec 1. [Epub ahead of print]

17. Maslach C, Jackson SE, Leiter MP. Maslach Burnout Inventory manual. $3^{a}$ ed. Palo Alto, California: Consulting Psychologists Press; 1996.

18. Taniguchi T, Hirokawa K, Tsuchiya M, Kawakami N. The immediate effects of 10 -minute relaxation training on salivary immunoglobulin $\mathrm{A}(\mathrm{s}-\mathrm{Ig} \mathrm{A})$ and mood state for Japanese female medical co-workers. Acta Med Okayama. 2007;61:139-45.

19. Baldwin L, Wagers C, Schwartz G. Reiki improves heart rate homeostasis in laboratory rats. J Altern Complement Med. 2008;14:417-22.
20. Lund I, Ge Y, Yu LC, Uvnas-Moberg K, Wang J, Yu C, Kurosawa M, Agren G, Rosén A, Lekman M, Lundeberg $\mathrm{T}$. Repeated massage-like stimulation induces long-term effects on nociception: contribution of oxytocinergic mechanisms. Eur J Neurosc. 2002;16:330-8.

21. Mansour AA, Beuche M, Laing G, Leis A, Nurse J. A study to test the effectiveness of placebo Reiki standardization procedures developed for a planned Reiki efficacy study. J Altern Complement Med. 1999;5:153-64.
Received: Jan. 21 2011 Accepted: June $14^{\text {th }} 2011$ 